\title{
Erratum to: Professor Barrie Vernon-Roberts, AO, MD, BSc, PhD, FRCPath, FRCPA, FAOrthA (Hon), FRS.SA
}

\author{
K. D. Rainsford • D. R. Haynes
}

Published online: 24 July 2013

(C) Springer Basel 2013

Erratum to: Inflammopharmacol (2013) 21:269-277

DOI 10.1007/s10787-013-0176-6

The original version of this article unfortunately contained a mistake. On the second page the first paragraph in the right column should read as follow:

"The ultimate accolade was the award to Professor Vernon-Roberts of the Officer of the Order of Australia (AO) in the General Division in the Queen's Birthday Honours".

The online version of the original article can be found under doi:10.1007/s10787-013-0176-6.

K. D. Rainsford ( $\square)$

Emeritus Professor, Biomedical Research Centre, Sheffield

Hallam University, Sheffield S1 1WB, UK

e-mail: k.d.rainsford@shu.ac.uk

D. R. Haynes

Discipline of Anatomy and Pathology, School of Medical

Sciences, Division of Health Sciences, University of Adelaide,

Frome Road, Adelaide, SA 5005, Australia

e-mail: david.haynes@adelaide.edu.au 